\title{
A Comparison Study of Sensible and Latent Thermal Energy Storage Used in Domestic Hot Water Solar Heating System
}

\author{
Josip Batista, Kristian Lenic, Anica Trp, Fran Torbarina \\ Department of Thermodynamics and Energy Engineering \\ University of Rijeka, Faculty of Engineering \\ Rijeka, Croatia \\ josip.batista@riteh.hr, kristian.lenic@ riteh.hr, anica.trp@ riteh.hr, fran.torbarina@riteh.hr
}

\begin{abstract}
Numerical analysis of domestic hot water solar system with sensible and latent thermal energy storages (TES), for specific residential building, has been presented in this paper. Numerical models of systems are developed in the Trnsys environment, consisting of the sensible or latent thermal energy storage tank, the flat-plate solar collectors, pump, differential controller and auxiliary heating source. Realistic meteorological conditions and standard user load profile were used as input parameters. The latent thermal energy storage tank contains sodium acetate trihydrate with added graphite powder, as phase change material (PCM), filled in cylindrical capsules and integrated into the tank, filling approximately $11 \%$ of total tank volume. The set of transient numerical simulations has been performed for a different tank volume and collector area ratios, ranging from 0.03 to $0.16 \mathrm{~m}^{3} / \mathrm{m}^{2}$. The performance of latent thermal energy storage system is compared with conventional sensible thermal energy storage system in terms of: collector efficiency, system efficiency, solar fraction and auxiliary energy consumption. The results of simulations indicate that latent thermal energy storage has advantages for specific tank volume to collector ratios, when the average temperature inside the tank is approaching the melting temperature of PCM.
\end{abstract}

Keywords-domestic hot water solar system, sensible thermal energy storage, latent thermal energy storage

\section{INTRODUCTION}

Today's society and the economy, in general, are based on abundant and reliable energy supplies. The average annual growth rate of the human population is approximately $1.5 \%$, thus increasing demand for energy resources. Recent predictions [1] estimate a steep increase in primary energy consumption by $48 \%$ in the European Union, until 2040. With a decline in fossil fuel supply and their negative impact on the environment, the world is seeking to find an efficient way of producing and consuming energy that would suppress coal, petroleum and other harmful energy carriers. The accelerated transition to renewable energy is in full swing and the best indicator is largest annual increase of renewable power generation capacity in 2018, with an estimated $181 \mathrm{GW}$ of capacity added [2]. Solar energy appearing on earth is the most fundamental renewable energy source in nature. It is characterized by a frequent discrepancy between the time of energy availability and the time of energy demand. This mismatch has necessitated the urge to design efficient and sustainable methods of storing energy. Thermal energy storage has become an important matter in the thermal energy systems and has been widely used to increase the thermal efficiency of different applications.

Domestic hot water (DHW) solar heating system is one of the most practical, economical and popular method of using solar energy in many developed countries. Solar collectors and thermal energy storage (TES) unit are central components in solar thermal applications [3]. According to different storage mechanisms, there are two basic types of systems: sensible and latent. Sensible TES is the more studied and developed technology [4-8]. The main feature of sensible TES in DHW systems is its capability to heat a stored amount of water without phase changing, dependent on its specific heat capacity and the temperature change. On the other hand, the latent TES has attracted a large number of applications in recent years, including domestic hot water application, due to much higher storage capacity and (near) isothermal energy transfer. Phase change materials (PCMs) have ability to store or release a high latent heat when re-forming their phase structures during processes of melting/solidfication or evaporation/condensation. For different applications there are differently suited PCMs [9]. Several papers reported experimental investigations on domestic hot water systems containing PCMs [10-12]. Results obtained in experiments showed that effect of PCM is beneficial to increase discharge period of the water tank.

Over the last decades, many papers have described different numerical models of PCM storage tanks in order to estimate their thermal behavior [13-16]. Some papers implemented a model of latent TES in a whole-building simulation environment [17-19], such as TRNSYS [20] or Energyplus [21].

In this work the set of transient numerical simulations has been performed for a different tank volume and collector area ratios, ranging from 0.03 to $0.16 \mathrm{~m}^{3} / \mathrm{m}^{2}$. The TRNSYS model developed by Schranzhofer et al. [17] has been used to simulate a heat transfer in domestic hot water tank with and without PCM modules.

\section{SYSTEM MODELING}

\section{A. System description}

The analysed system, as shown in Fig. 1, consists of a sensible and latent thermal energy storage tanks, the flat-plate solar collectors, a pump, differential controller and auxiliary 
electric heater. Either sensible or latent TES is used when the system is running. A pump circulates a heat-transfer fluid through the collectors, which absorb solar radiation and convert it to usable thermal energy of the working fluid. The heat carried by the working fluid is exchanged to potable water using an internal heat exchanger, either in a sensible or latent thermal energy storage. Differential control has been used as a function of the difference between upper and lower input temperatures. Lower input temperature is the cold tank side temperature and the upper input temperature is the solar collector outlet temperature. Upper and lower dead bands for temperature difference are set to be $10{ }^{\circ} \mathrm{C}$ and $2{ }^{\circ} \mathrm{C}$, respectively. However, the pump stops if temperature at the top of the tank exceeds $90{ }^{\circ} \mathrm{C}$. When the water outlet from the tank is warmer than set point temperature, a 3-way temperature control mixing valve will add cold water to adjust the temperature. Hot water from the tank flows through an auxiliary heater outside the storage tank, with a heating output of $4.5 \mathrm{kWIf}$ the water outlet temperature from the tank is bellow $45^{\circ} \mathrm{C}$, the auxiliary heater will turn on.

The size of all equipment and average daily water consumption used in this study was determined considering a type of residential building. The system is designed for a small multy-family residential building containing four apartment units, located in Mediterranean coastal region.
The volume of the tank is determined as a standard 3001 with height of $1.9 \mathrm{~m}$, internal diameter of $0.48 \mathrm{~m}$ and $8 \mathrm{~cm}$ thick insulation layer with conductivity of $0.04 \mathrm{~W} /(\mathrm{mK})$. The collectors are oriented directly towards the equator with the slope equal to $45^{\circ}$. The total collectors surface area varies between $1.9 \mathrm{~m}^{2}$ and $9.5 \mathrm{~m}^{2}$, when one and five collectors are used, respectively.

The simulations were performed using TRNSYS simulation software. Weather and meteorological data for selected location (latitude $43^{\circ} 30^{\prime} 29^{\prime \prime} \mathrm{N}$ ) were generated using Meteonorm. These data are based on monthly values that Meteonorm generates stochastically to hourly values.

Typical domestic hot water load profile for European Union, investigated in 2008 within the Annex 42 by the International Energy Agency (IEA) [22], is used in this study (Fig. 2). The figure shows that water consumption is particulary high between 6-9 a.m., and around 10 p.m. Using this profile, the overall daily consumption was normalized to 7001 of hot water per day, for all four apartments.

When system is operating with latent TES, sodium acetate trihydrate with added graphite powder is used as a PCM. This material has several properties which makes it suited for use in DHW systems, as reported in [23]:

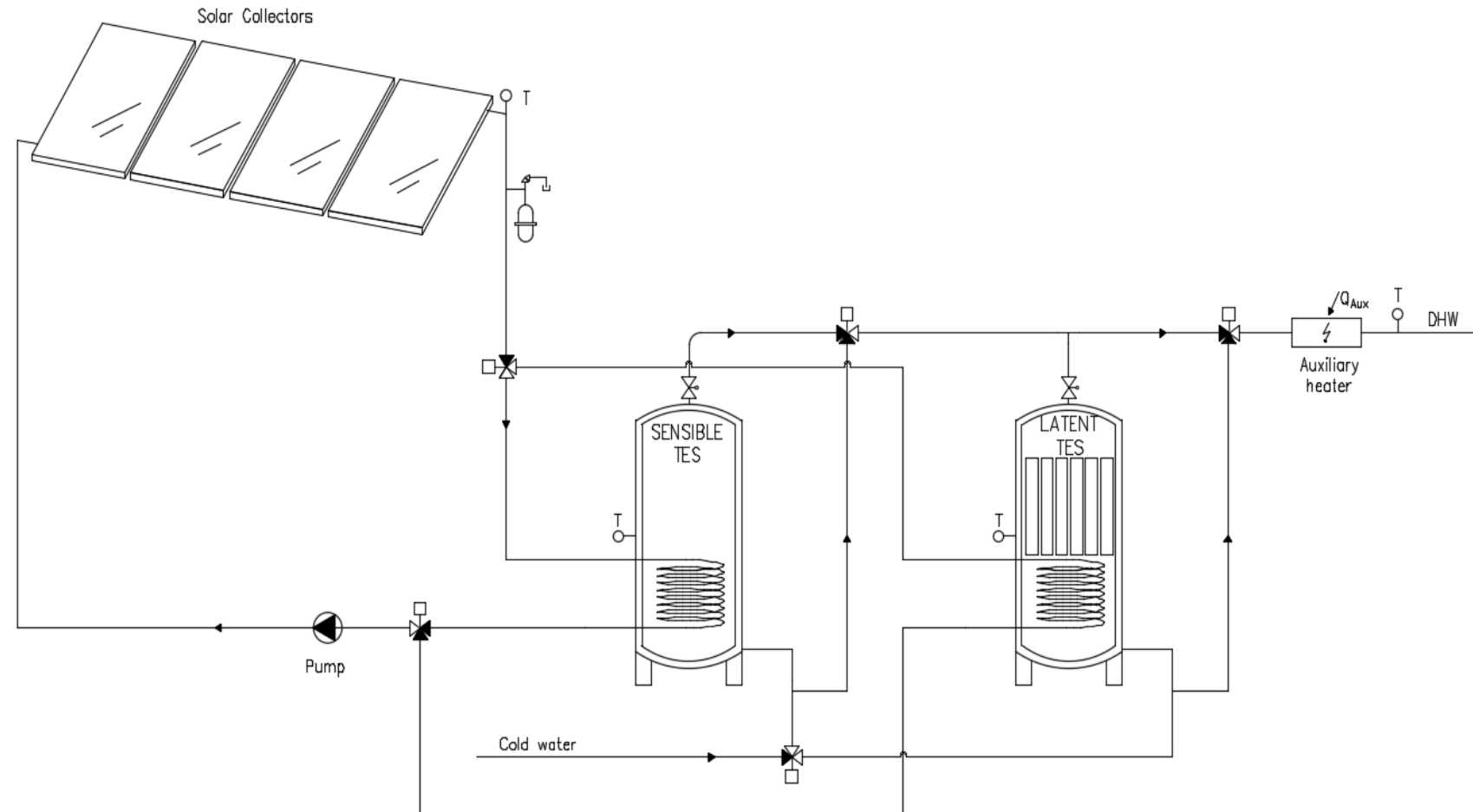

Figure 1 Layout of the DHW system with sensible and latent TES 


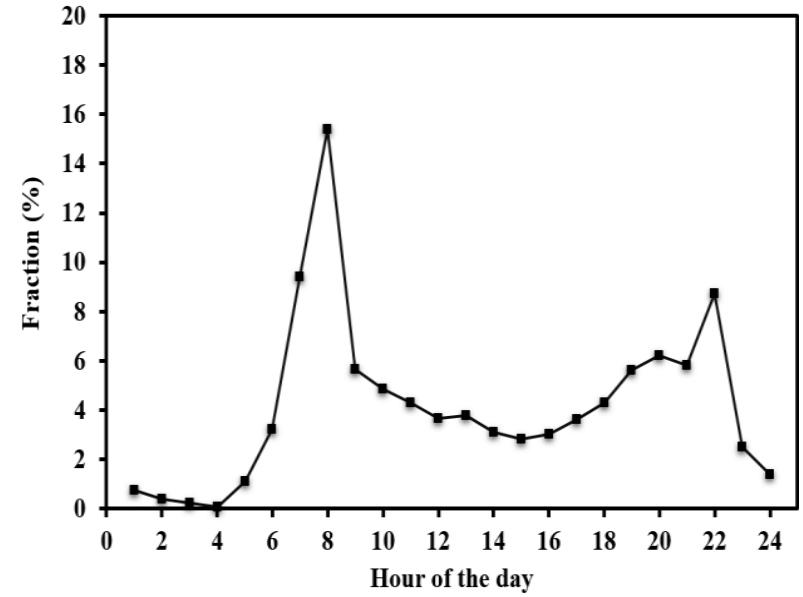

Figure 2 Residential daily DHW consumption profile according [22]

- it has a high latent heat $(180-200 \mathrm{~kJ} / \mathrm{kg})$,

- it has melting temperature between $56^{\circ} \mathrm{C}$ and $60{ }^{\circ} \mathrm{C}$

- it is nontoxic,

- it is inexpensive,

- $\quad$ it has the ability of supercooling.

The calculation geometry of PCM module is a filled cylinder of diameter $33 \mathrm{~mm}$. Total of 30 PCM modules are integrated inside the tank, filling approximately $11 \%$ of total tank volume. By increasing number of PCM modules, heat transfer surface area between PCM and water increases, which subsequently leads to increasing in the fraction of melted PCM inside the tank. Aluminium has been chosen as a material for PCM module.

\section{B. Calculation model of solar collector and heat storage}

The solar collector model is based on a efficiency equation:

$$
\eta_{C}=\eta_{\mathrm{C} 0}-\eta_{\mathrm{C} 1} \cdot X_{1}-\eta_{\mathrm{C} 2} \cdot X_{2} .
$$

Here, parameters $\eta_{\mathrm{CO}}, \eta_{\mathrm{C} 1}$ and $\eta_{\mathrm{C} 2}$ were taken from the performance data of real collectors (Table 1). The normalized temperature differences $X$ are defined as:

$$
\begin{gathered}
X_{1}=\frac{T_{C, \text { in }}+T_{C, \text { out }}-T_{a}}{2 \cdot I_{T}}, \\
X_{2}=\frac{\left(T_{C, \text { in }}+T_{C, \text { out }}-2 \cdot T_{a}\right)^{2}}{4 \cdot I_{T}},
\end{gathered}
$$

where, $T_{C, \text { in }}$ and $T_{C \text {,out }}$ are inlet and outlet collector temperatures of the working fluid and $I_{T}$ denotes incident solar flux.

Table 1 Solar collector data

\begin{tabular}{|c|c|}
\hline Collector area $A_{c}$ & $1.9 \mathrm{~m}^{2}$ \\
\hline Intercept efficiency $\eta_{C 0}$ & 0.79 \\
\hline Efficiency slope $\eta_{C 1}$ & $3.02 \mathrm{~W} / \mathrm{m}^{2} \mathrm{~K}$ \\
\hline Efficiency curvature $\eta_{C 2}$ & $0.0228 \mathrm{~W} / \mathrm{m}^{2} \mathrm{~K}^{2}$ \\
\hline Mass flow density $g$ & $0.014 \mathrm{~kg} / \mathrm{s} \mathrm{m}^{2}$ \\
\hline
\end{tabular}

A general equation for solar thermal collectors is provided from the collector energy balance:

$$
\eta_{C} \cdot A_{C} \cdot I_{T}=G_{w} \cdot c_{w} \cdot\left(T_{C, \text { out }}-T_{C, \text { in }}\right) .
$$

The model of the storage tank is designed using enthalpy approach, in which the specific enthalpy $h(\mathrm{~J} / \mathrm{kg})$ is a function of the temperature $T$.

The model of the mass and energy conservation in the storage tank assumes that the problem is one-dimensional, with variations in temperature only in the vertical direction. In the multinode approach, the storage tank is divided into $\mathrm{N}$ isothermal horizontal layers and each layer contains water and PCM, except the top and bottom layers, that do not contain PCM in order to avoid direct losses from the PCM to environment (see Fig. 3). The greater the number of nodes, the greater is the stratification phenomena, but simulations may slow down dramatically. Each node (j) is characterized by its mass $m_{j}$, specific enthalpy $h_{j}$ and temperature $T_{j}$. The energy balance of the $j$-th storage node leads to the time evolution of the enthalpy $h_{j}$ :

$$
m_{j} \frac{h_{j}^{(t+\Delta t)}-h_{j}^{(t)}}{\Delta t}=\dot{Q}_{d p, j}^{(t)}+\dot{Q}_{h x, j}^{(t)}+\dot{Q}_{\text {cond }, j}^{(t)}+\dot{Q}_{\text {loss }, j}^{(t)}+\dot{Q}_{p c m, j}^{(t)}
$$

In this equation, the subscripts denote the entalpy change due to charging or discharging by double port conections (dp), internal heat exchangers (hx), heat conduction to neighboring nodes (cond), heat losses to the ambient (loss) and possible PCM modules inside the tank ( $\mathrm{pcm})$. The superscripit $t$ on the right hand side denotes that new enthalpy of node $j$ at time $t+\Delta t$ is evaluated by quantities only at the old time $t$, i.e. that explicit scheme is used.

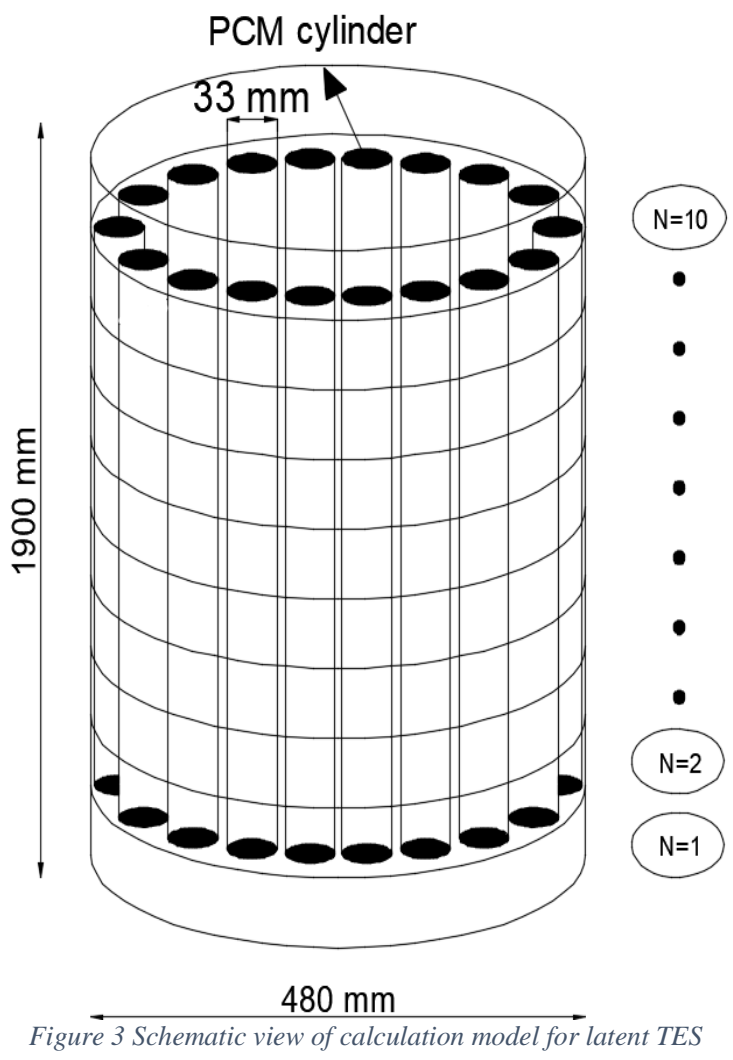


The enthalpy change in time due to one-dimensional unsteady heat conduction to adjacent nodes is governed by the following expression:

$$
m_{j}\left[\frac{h_{j}(t+\Delta t)-h_{j}(t)}{\Delta t}\right]_{\text {cond }}=\frac{k \cdot A}{\Delta z}\left(T_{j-1}-2 T_{j}+T_{j+1}\right) .
$$

Here, $A$ is the cross section area of the storage tank, $\Delta z$ is the height of one storage node, and $k$ is a thermal conductivity. Equation (6) only applies if the density is constant. Finally, enthalpy change of the storage node $j$ in time due to PCM modules, when filled cylinders are observed, is given by:

$$
m_{j}\left[\frac{h_{j}(t+\Delta t)-h_{j}(t)}{\Delta t}\right]_{p c m}=-N_{P C M}\left[(U A)_{P C M}\left(T_{j}-T_{n_{r} j}\right)\right] .
$$

Besides horizontal layers, PCM modules are divided into radial layers. The number of radial nodes of PCM module is denoted by $n_{r}$. In order to acquire the node temperature, the heat equation (8) must be solved, for which cylindrical coordinates are taken and there is no dependence on the angular coordinate, i.e. fully mixed nodes are assumed :

$$
\rho c_{p} \frac{\partial T}{\partial t}=\frac{1}{r} \frac{\partial}{\partial r}\left(k r \frac{\partial T}{\partial r}\right)+\frac{\partial}{\partial z}\left(k \frac{\partial T}{\partial z}\right) .
$$

\section{System performance}

The thermal performance of a DHW solar heating system is generally described in terms of a monthly solar thermal collector efficiency (4) and a solar fraction, which is defined as the fraction of the total needed energy that is supplied by solar system:

$$
f=\frac{Q_{\text {load }}-Q_{\text {auxiliary }}}{Q_{\text {load }}},
$$

where, $Q_{\text {load }}$ is needed thermal energy for DHW preparation and $Q_{\text {auxiliary }}$ is the auxiliary energy supplied to the system. Additional energy associated with running the other components of the system (e.g. pump and controller) is not considered in this study.
Another common performance indicator is monthly solar system efficiency, which is defined as:

$$
\eta_{s}=\frac{Q_{\text {solar }}}{A_{C} \cdot I_{T} \cdot \Delta t}
$$

The solar system efficiency describes the ratio between the monthly amount of energy supplied to the heat storage through an internal heat exchanger $Q_{\text {solar }}$ and the global radiative heat on the solar collectors $A_{C} I_{T} \Delta t$.

\section{RESULTS AND DISCUSSION}

Total of 10 simulation cases were performed using TRNSYS simulation program, varying the tank volume to collector area ratios, ranging from 0.03 to $0.16 \mathrm{~m}^{3} / \mathrm{m}^{2}$, with constant volume of the tank of 3001 . A comparison of a different cases regarding the auxiliary electrical energy consumption is given in Table 2. Predictably, both sensible and latent TES solar heating systems require more auxiliary energy relating to the reduction of a total absorbing area of collectors, i.e. increasing $V_{t} / A_{c}$ ratio. Results related to consumption of auxiliary energy show an advantage for the system with PCM, when the tank volume to collector area ratio is $0.03 \mathrm{~m}^{3} / \mathrm{m}^{2}$. Case 4 also demonstrates slight beneficial impact of PCM.

When the tank volume to collector area ratio increases, the efficiency of the collector and the system also increase, due to decrease in average temperature of the working fluid and storage medium, which leads to better absorption of thermal energy in solar heating loop, i.e. lower rate of heat loss from collector to ambient (Figs. 4 and 5).

Table 2 Required auxiliary energy for DHW system

\begin{tabular}{|c|c|c|c|c|}
\hline & $\begin{array}{c}\mathbf{V}_{\mathbf{t}} / \mathbf{A}_{\mathbf{c}} \\
\left(\mathbf{m}^{\mathbf{3}} / \mathbf{m}^{\mathbf{2}}\right)\end{array}$ & $\begin{array}{c}\text { Required aux. } \\
\text { energy - Sensible } \\
\text { TES (MJ) }\end{array}$ & $\begin{array}{c}\text { Required aux. } \\
\text { energy - Latent } \\
\text { TES (MJ) }\end{array}$ & $\begin{array}{c}\text { Gain } \\
(\mathbf{\%})\end{array}$ \\
\hline Case 1 & 0.16 & 26165.9 & 26419.3 & +0.96 \\
\hline Case 2 & 0.08 & 19013.5 & 19184.4 & +0.90 \\
\hline Case 3 & 0.05 & 13412.6 & 13429.5 & +0.12 \\
\hline Case 4 & 0.04 & 9507.3 & 9439.5 & -0.7 \\
\hline Case 5 & 0.03 & 7326.7 & 7044.6 & -4.0 \\
\hline
\end{tabular}

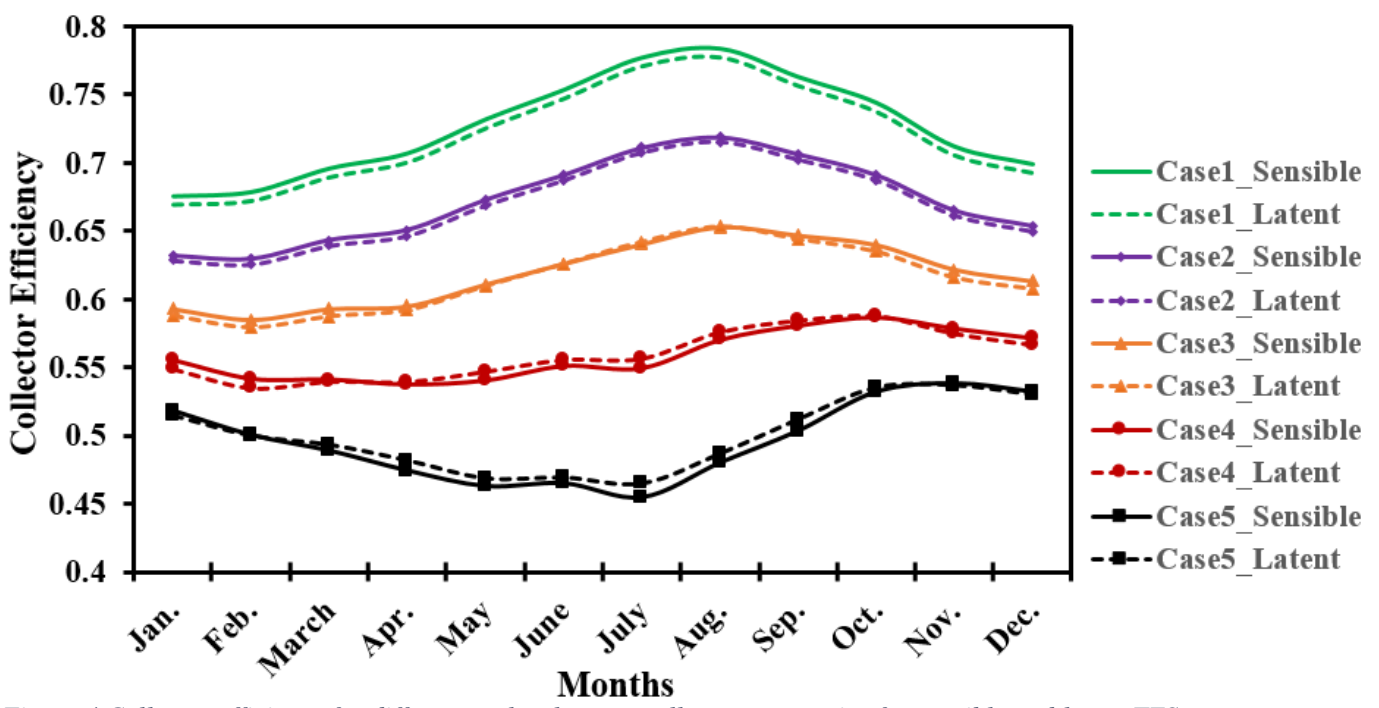

Figure 4 Collector efficiency for different tank volume to collector area ratios for sensible and latent TES 


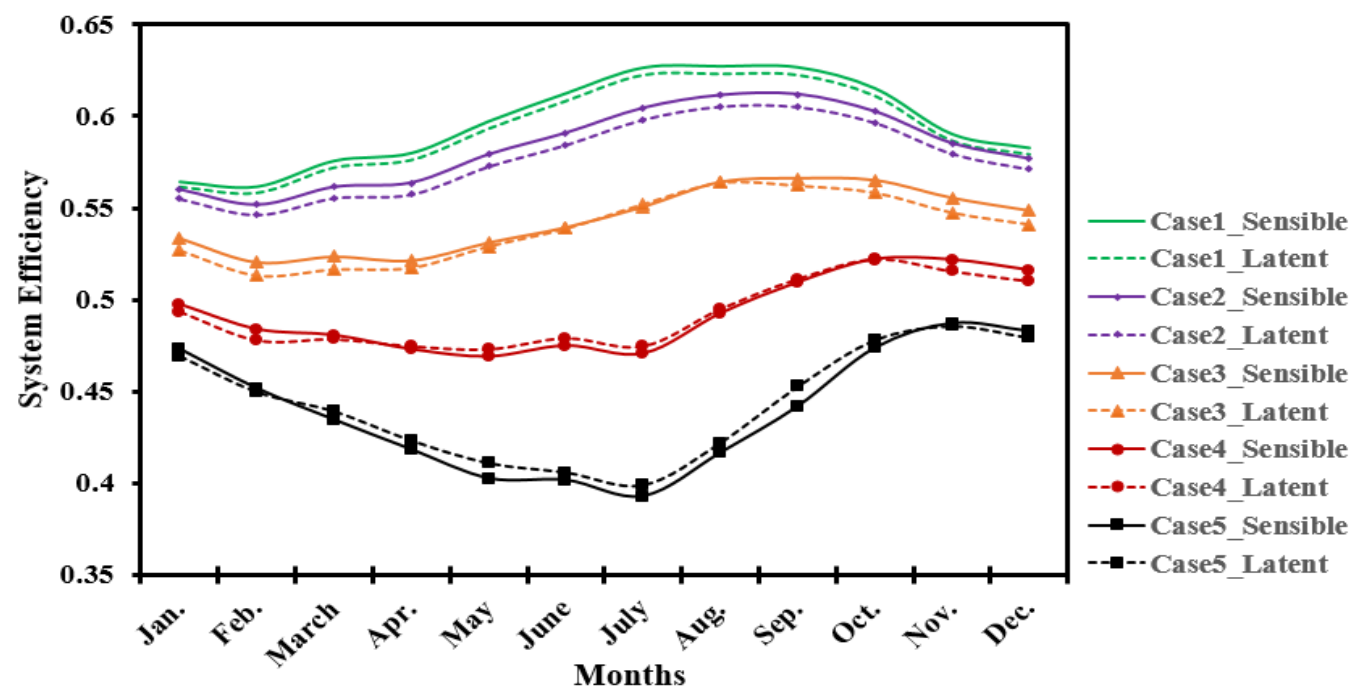

Figure 5 System efficiency for different tank volume to collector area ratios for sensible and latent TES

Latent TES solar system performs a slight increase of collector and system efficiency when small $V_{t} / A_{c}$ has been used (case 5). This is due to the fact that the average temperature inside the storage tank is higher and it is near melting range of PCM most of the year, Fig. 6. Therefore, presence of phase change has a beneficial influence, leading to return of a cold water to the collector and consequently increased collector efficiency.

The result of monthly solar fraction for two different ratios $V_{t} / A_{c}$ (extreme cases) is showed in Fig. 7. The results show that for a system with water and PCM, an $9.5 \mathrm{~m}^{2}$ solar collector $\left(V_{t} / A_{c}=0.03 \mathrm{~m}^{3} / \mathrm{m}^{2}\right)$ is able to supply over $90 \%$ of the hot water demand from May to September and over $80 \%$ from March to October. On the contrary, an $1.9 \mathrm{~m}^{2}$ solar collector $\left(V_{t} / A_{c}=0.16 \mathrm{~m}^{3} / \mathrm{m}^{2}\right)$ reduces solar fractions by 58 $65 \%$ between March and October. A simulation in which $V_{t} / A_{c}$ was set to $0.03 \mathrm{~m}^{3} / \mathrm{m}^{2}$ showed the beneficial impact of PCM on a system performance, unlike the case with ratio $V_{t} / A_{c}$ equal

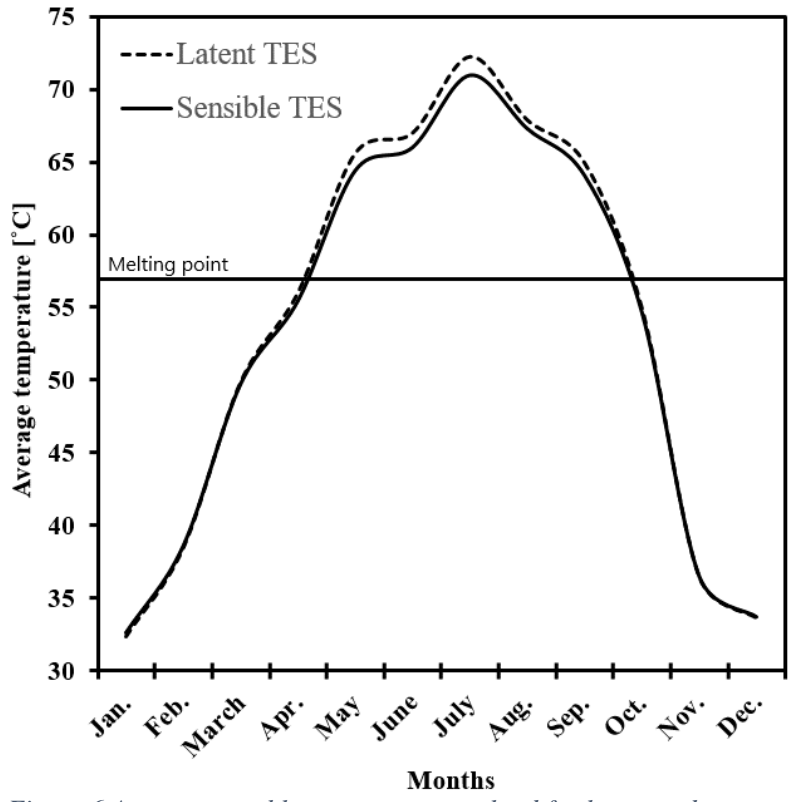

Figure 6 Average monthly temperatures to load for latent and sensible TES $\left(V_{t} / A_{c}=0.03 \mathrm{~m}^{3} / \mathrm{m}^{2}\right)$
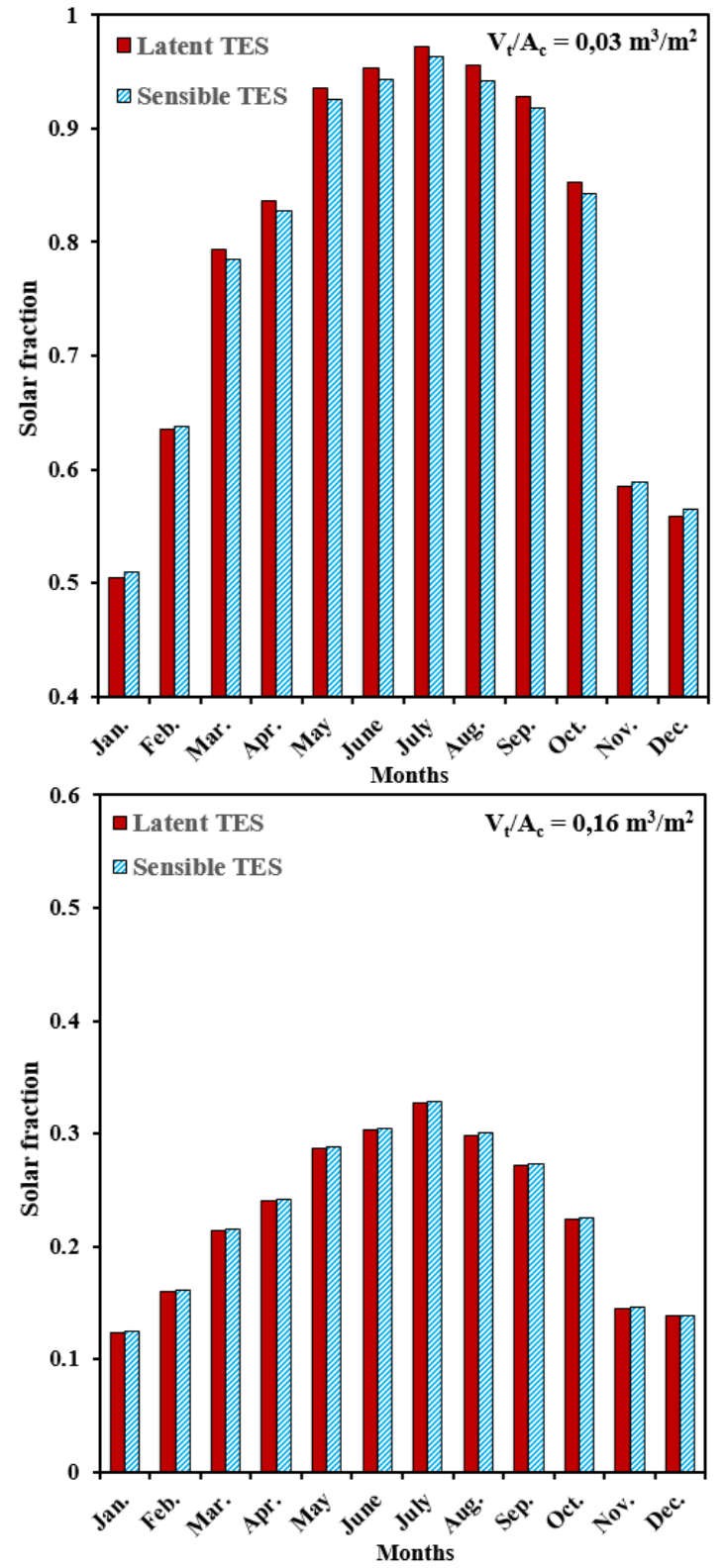

Figure 7 Monthly solar fractions for different tank volume to collector area ratios, $V_{t} / A_{c}=0.03 \mathrm{~m}^{3} / \mathrm{m}^{2}$ (case 5) and $V_{t} / A_{a}=0.16 \mathrm{~m}^{3} / \mathrm{m}^{2}$ (case 1 ) 
to $0.16 \mathrm{~m}^{3} / \mathrm{m}^{2}$. Furthermore, it indicates the key role that ratio $V_{t} / A_{c}$ has on the system solar fraction. The results show that conclusions regarding the impact of PCM on solar fraction are strongly dependent on a ratio $V_{t} / A_{c}$.

The improved performance of the system with latent storage tank can be explained by considering 24-hour water temperature evolution of the top and bottom layers of the sensible and latent storage tank for a typical spring day, as shown in Figs. 8 and 9. An enhanced solar fraction is attributed to the lower temperatures of the bottom of the latent storage tank and the working fluid that comes out of heat exchanger, when phase change occurs. Increased outlet water temperature from the tank, during early morning peaks, revealed the benefits of PCM at lower ratios of $V_{t} / A_{c}$, for particular system configuration that was considered.

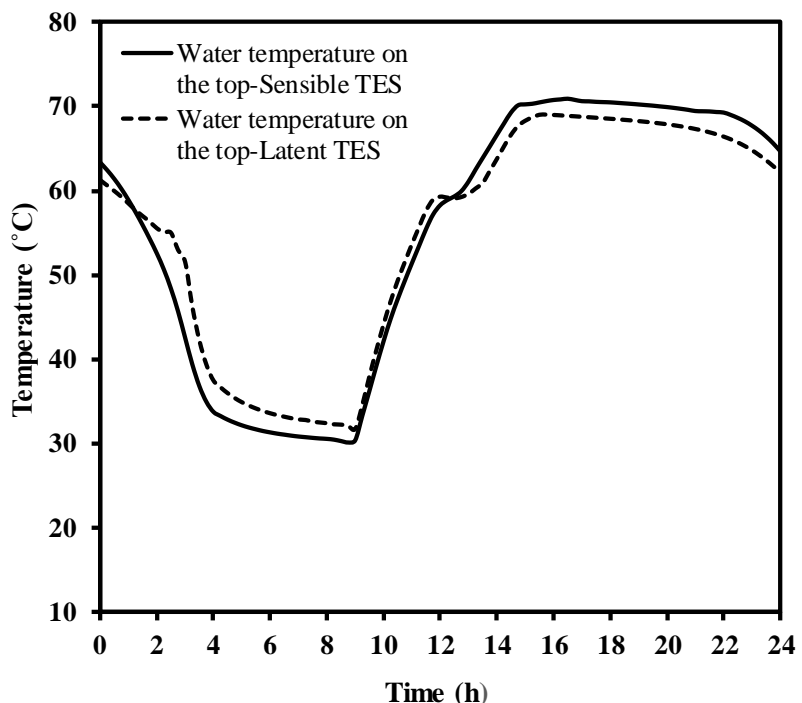

Figure 8 Top tank water temperature on 24-hour period for a typical spring day (case 5)

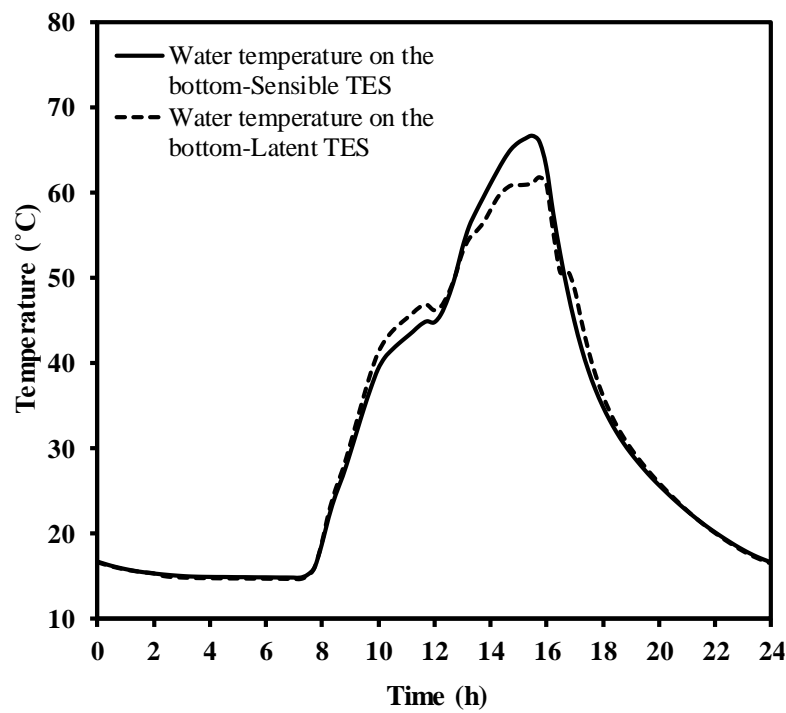

Figure 9 Bottom tank water temperature on 24-hour period for a typical spring day (case 5 )

\section{CONCLUSION}

This study presented the significance of PCM in standard domestic hot water tank designed for a multy-family residential building, for different tank volume and collector area ratios. A modeling of the system was carried out using TRNSYS software under the meteorological conditions of the mediterranean coastal region. For the system under consideration, latent TES system could yield benefits in comparison with sensible TES system when the rate of tank volume to collector area is below $0.04 \mathrm{~m}^{3} / \mathrm{m}^{2}$, in terms of auxiliary energy required, solar system efficiency and solar fraction. The exact ratio after which PCM provides benefits is not universal. It may vary according to different conditions, e.g. daily DHW consumption, demand profile, meteorological conditions, properties of storage tank and solar collector, amount and type of PCM, etc. In conclusion, the use of PCM in DHW solar heating system seems a promising technology, but requires detailed analysis in design process.

\section{ACKNOWLEDGMENT}

This work has been suported in part by Croatian Science Foundation under the project HEXENER (IP-2016-06-4095) and in part by the University of Rijeka under the project number ,uniri-tehnic-18-69“.

\section{REFERENCES}

[1] European Commission. European Union Energy in Figures; Statistical Pocketbook; Publications Office of the EU: Luxembourg, Luxembourg, 2018.

[2] REN21.2019., Renewables 2019 Global Status Report, Paris, 2019

[3] Y. Tian, C.Y. Zhao, "A review of solar collectors and thermal energy storage in solar thermal applications", Applied Energy, vol. 104, 2013, pp. 538-553.

[4] V. Basecq, G. Michaux, C. Inard, P. Blondeau, "Short-term storage systems of thermal energy for buildings: a review", Advances in Building Energy Research, vol. 7(1), 2013, pp. 66-119.

[5] P.D. Lund, "A general design methodology for seasonal storage solar systems", Solar Energy, vol 31(3), 1989, pp. 235-251.

[6] M.C. Rodríguez-Hidalgo, P.A. Rodríguez-Aumente, A. Lecuona, M. Legrand, R. Ventas, "Domestic hot water consumption vs. solar thermal energy storage: The optimum size of the storage tank", Applied Energy, vol. 97, 2012, pp. 897-906.

[7] Y.M. Han, R.Z. Wang, Y.J. Dai, "Thermal stratification within the water tank", Renewable and Sustainable Energy Reviews, vol. 13(5), 2009, pp. 1014-1026.

[8] R. Spur, D. Fiala, D. Nevrala, D. Probert, "Performances of modern domestic hot-water stores", Applied Energy, vol. 83(8), 2006, pp. 893910.

[9] B. Zalba, J.M. Marin, L.F. Cabeza, H. Mehling, "Review on thermal energy storage with phase change: materials, heat transfer analysis and applications", Applied Thermal Engineering, vol. 23(3), 2003, pp. 251283.

[10] N. Nallusamy, S. Sampath, R. Velraj, "Experimental investigation on a combined sensible and latent heat storage system integrated with constant/varying (solar) heat sources", Renewable Energy, vol 32(7), 2007, pp. 1206-1227.

[11] M. Mazman, L.F. Cabeza, H. Mehling, M. Nogues, H. Evliya, H.O. Paksoy, "Utilization of phase change materials in solar domestic hot water systems", Renewable Energy, vol. 34(6), 2009, pp. 1639-1643.

[12] L. Navarro, C. Barreneche, A. Castell, D.A.G. Redpath, P.W. Griffiths, L.F. Cabeza, "High density polyethylene spheres with PCM for domestic hot water applications: Water tank and laboratory scale study", Journal of Energy Storage, vol 13, 2017, pp. 262-267.

[13] V.R. Voller, M. Cross, N.C. Markatos, "An enthalpy method for convection/diffusion phase change", International Journal for Numerical Methods in Engineering”, vol 24(1), 1987, pp. 271-284.

[14] A. Trp, K. Lenic, B. Frankovic, "Analysis of the influence of operating conditions and geometric parameters on heat transfer in water-paraffin 
shell-and-tube latent thermal energy storage unit", Applied Thermal Engineering, vol 26(16), 2006, pp. 1830-1839.

[15] A. de Gracia, E. Oró, M.M. Farid, L.F. Cabeza, "Thermal analysis of including phase change material in a domestic hot water cylinder", Applied Thermal Engineering, vol 31(17-18), pp. 3938-3945.

[16] T. Bouhal, T. El Rhafiki, T. Kousksou, A. Jamil, Y. Zeraouli, "PCM addition inside solar water heaters: Numerical comparative approach", Journal of Energy Storage, vol 19, 2018, pp. 232-246.

[17] H. Schranzhofer, P. Puschnig, A. Heinz, W. Streicher, "Validation of a Trnsys simulation model for pcm energy storages and $\mathrm{pcm}$ wall construction elements", in: Ecostock, 2006.

[18] J. Bony, S. Citherlet, "Numerical model and experimental validation of heat storage with phase change materials", Energy and Buildings, vol 39(10), 2007, pp. 1065-1072.

[19] J.F.Belmonte, P. Eguía, A.E. Molina, J.A. Almendros-Ibáñez, R. Salgado, "A simplified method for modeling the thermal performace of storage tanks containing PCMs", Applied Thermal Engineering, vol 95, 2016, pp. 394-410.
[20] S.A. Klein, W.A. Beckman, J.W. Mitchell, et al., "TRNSYS 18. A TRaNsient System Simulation program", Solar Energy Laboratory, University of Wisconsin-Madison, 2017.

[21] DOE, Energyplus, Version 8.3, U.S. Department of Energy. Energy Simulation Software, 2015.

[22] I.K. Knight, N. Manning, M. Swinton, M.R. Hajo, European and Canadian non-HVAC electric and DHW load profiles for use in simulating the performance of residential cogeneration systems, Energy conservation in buildings and community systems programme, IEA Annex; 42(6):84, 2007.

[23] J.B. Johansen, M. Dannemand, W. Kong, J. Fan, J. Dragsted, S. Furbo, Thermal conductivity enhancement of sodium acetate trihydrate by adding graphite powder and the effect on stability of supercooling, Energy Procedia, vol 70, 2015, pp. 249-256.

$\begin{array}{ll}\text { Nomenclature } \\ \text { Latin symbols } \\ A & \text { area } \\ c & \text { specific heat } \\ f & \text { fraction } \\ G & \text { mass flow rate } \\ g & \text { mass flow density } \\ h & \text { specific enthalpy } \\ I_{T} & \text { global radiation incident on the solar collector } \\ k & \text { thermal conductivity } \\ m & \text { mass } \\ N & \text { number of PCM modules } \\ Q & \text { thermal energy } \\ r & \text { radius } \\ T & \text { temperature } \\ t & \text { time } \\ U & \text { overall heat transfer coefficient } \\ X & \text { normalized temperature difference } \\ z & \text { thickness of one storage node }\end{array}$

\begin{tabular}{|c|c|c|}
\hline & & \\
\hline$\left(\mathrm{m}^{2}\right)$ & $\Delta$ & element of area or time \\
\hline$(\mathrm{J} / \mathrm{kgK})$ & $\eta$ & efficiency \\
\hline
\end{tabular}

$(-)$

$(\mathrm{kg} / \mathrm{s})$

$\left(\mathrm{kg} / \mathrm{sm}^{2}\right)$

$(\mathrm{J} / \mathrm{kg})$

$\left(\mathrm{W} / \mathrm{m}^{2}\right)$

$(\mathrm{W} / \mathrm{mK})$

$(\mathrm{kg})$

$(-)$

(J)

(m)

(K)

(s)

$\left(\mathrm{W} / \mathrm{m}^{2} \mathrm{~K}\right)$

$\begin{array}{ll}\text { Subscripts and superscripts } \\ a & \text { ambient } \\ \mathrm{C} & \text { collector } \\ \text { in } & \text { inlet } \\ \mathrm{j} & \text { node index } \\ \text { out } & \text { outlet } \\ \text { PCM } & \text { phase change material } \\ \mathrm{s} & \text { system } \\ \mathrm{w} & \text { water }\end{array}$

$\left(\mathrm{m}^{2} \mathrm{~K} / \mathrm{W}\right),\left(\mathrm{m}^{2} \mathrm{~K}^{2} / \mathrm{W}\right)$

(m) 